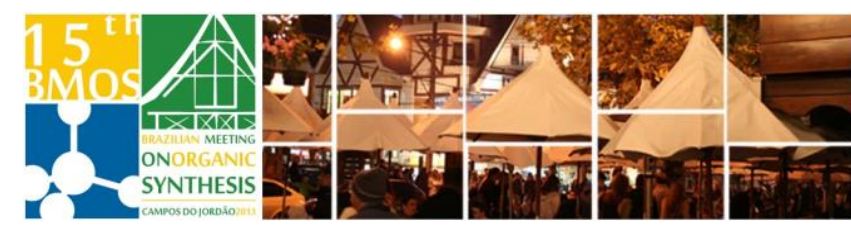

\title{
Synthesis of meso- $N$-Phenylmaleimide-porphyrins
}

\author{
Fabiane A. B. dos Santos, Carla M. B. Carvalho, Edjane R. dos Santos, \\ Timothy J. Brocksom and Kleber T. de Oliveira* \\ Universidade Federal de São Carlos - UFSCar, Departamento de Química, 13565-905, São Carlos, SP, \\ Brazil. \\ *e-mail: kleber.oliveira@ufscar.br; www.lqbo.ufscar.br
}

Keywords: Porphyrins, Maleimides, Dyads

\section{INTRODUCTION}

Porphyrin assemblies are attractive building blocks for modular construction of electronic and optical devices, chemical sensors and solar energy

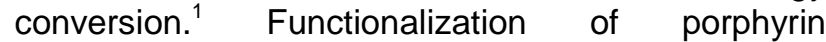
derivatives at the meso-position has been a subject of major interest in the last decades, since it allows for the improvement of the photophysical parameters. Following on our research group's interest on the study of the imide function in tetrapyrrolic derivatives, ${ }^{2}$ we have now explored the synthesis and optical properties of two new porphyrins meso-substituted with phenylmaleimide (7 and 9) (Scheme 2), prepared from the maleimide 5 (Scheme 1). Compounds 7 and 9 may constitute potential building blocks to synthesize dyads, triads or tetrads with improved photophysical and electrochemical properties for use as chemical sensors as well as photosensitizing materials. ${ }^{3}$

\section{RESULTS AND DISCUSSION}

Compound 1 was protected with ethanedithiol/PTSA (89\% yield) and then reduced with $\mathrm{SnCl}_{2} \cdot 2 \mathrm{H}_{2} \mathrm{O}(93 \%$ yield) (Scheme 1). The protected amine 3 was reacted with maleic anhydride ( $84 \%$ yield) and the amide-ester cyclized to 4 using $\mathrm{Ac}_{2} \mathrm{O} / \mathrm{NaOAc}$ with heating at $90^{\circ} \mathrm{C}(92 \%$ yield). The deprotected maleimide 5 was obtained from 4 and NBS/acetonewater $(87 \%)$. Compound 5 was used as the starting aldehyde for the synthesis of porphyrins 7 and $\mathbf{9}$, using the Lindsey methodology $\left(\mathrm{BF}_{3} . \mathrm{Et}_{2} \mathrm{O}\right.$ and $p$ chloranil as the oxidant) (7, 22\%, and 9, $34 \%$ yields). Porphyrins 7 and $\mathbf{9}$ were purified on silica gel and characterized by ${ }^{1} \mathrm{H}$ NMR and UV-Vis. We intend to perform Diels-Alder reactions with compounds $\mathbf{7}$ and 9 and several dienes in order to synthesize new dyads.

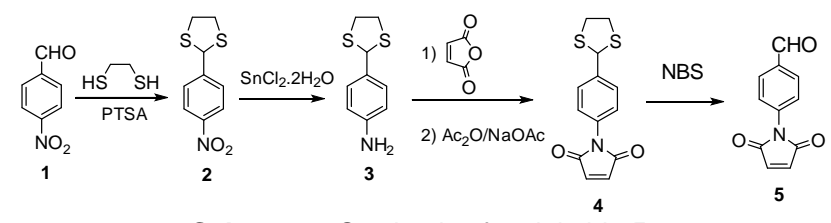

Scheme 1: Synthesis of maleimide 5 .

$15^{\text {th }}$ Brazilian Meeting on Organic Synthesis $-15^{\text {th }}$
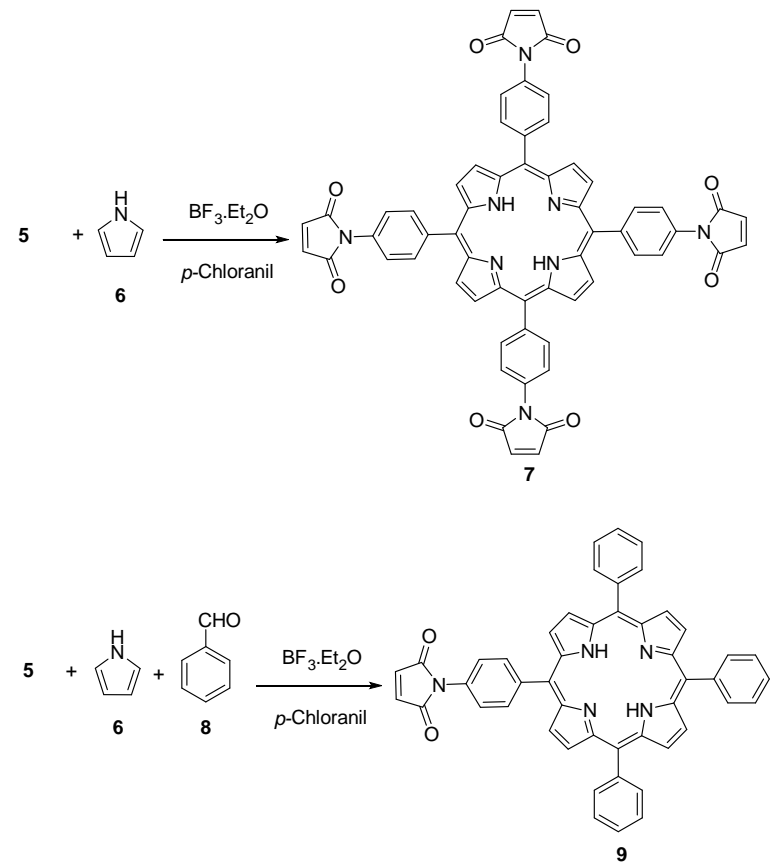

Scheme 2: Synthesis of Porphyrins 7 and 9.

\section{CONCLUSION}

The synthesis of two new porphyrins starting from the phenylmaleimide $\mathbf{5}$ was performed through a classical method, with high yields for porphyrin chemistry. The presence of the phenylmaleimide unit in the meso-position is strategic for the obtainment of different adducts, allowing low aggregation in solutions and interesting UV-Vis spectra.

\section{ACKNOWLEDGEMENTS}

The authors thank FAPESP (2013/06532-4 and 2011/13993-2), CNPq and CAPES for financial support. Thanks are also due to CNPq for F.A.B. Santos's scholarship.

\section{REFERENCES}

${ }^{1}$ (a) Stich M. I. J., Fischer L. H., Wolfbeis O. S.; Chem. Soc. Rev. 2010, 39, 3102. (b) Senge M. O., Fazekas M., Notaras E. G. A., Blau W. J., Zawadzka M., Locos O. B., Mhuircheartaigh E. M. N.; Adv. Mater. 2007, $19,2737$.

${ }^{2}$ dos Santos F A.B.,. Uchoa A. F,. Baptista M. S, lamamoto Y, Serra O. A, Brocksom T. J, de Oliveira K T.; Dyes and Pigments 2013, 99, 402.

${ }^{3}$ Carvalho C. M. B., Santos S. M,. Neves M. G. P. M. S, Tomé A. C., Silva A. M. S., Rocha J, Cavaleiro J. A. S; J. Org. Chem. 2013,78, 6622. 